\title{
Massive Idiopathic Pneumoperitoneum in Children: A Case Report
}

\author{
Sourou Bruno Noukpozounkou ${ }^{1}$, Yacoubou Imorou Souaibou ${ }^{2}$, \\ Amoussou Sedjro Clotaire Romeo Houegban1, Houenoukpo Koco', Orion Akokpe1, \\ Michel Armand Fiogbe ${ }^{1}$
}

\footnotetext{
${ }^{1}$ University Clinic of Pediatric Surgery, National University Hospital Center "Hubert Koutoukou Maga", Cotonou, Benin ${ }^{2}$ University Clinic of Visceral Surgery “A”, National University Hospital Center “Hubert Koutoukou Maga”, Cotonou, Benin Email: `brunopasca197@yahoo.fr, imorouyacoubou@yahoo.fr, houegbanromeo@gmail.com, houenoukpo13@gmail.com, akokpeorion@gmail.com,michfiogbe@yahoo.fr
}

How to cite this paper: Noukpozounkou, S.B., Imorou Souaibou, Y., Houegban, A.S.C.R., Koco, H., Akokpe, O. and Fiogbe, M.A. (2018) Massive Idiopathic Pneumoperitoneum in Children: A Case Report. Open Journal of Pediatrics, 8, 249-254. https://doi.org/10.4236/ojped.2018.83026

Received: July 11, 2018

Accepted: September 3, 2018

Published: September 6, 2018

Copyright $\odot 2018$ by authors and Scientific Research Publishing Inc. This work is licensed under the Creative Commons Attribution International License (CC BY 4.0).

http://creativecommons.org/licenses/by/4.0/

\begin{abstract}
The pneumoperitoneum is the abnormal presence of free air in the peritoneal cavity. In most cases it is related to the perforation of hollow organs. Nevertheless there are cases of pneumoperitoneum without obvious causes called idiopathic. We report a case of massive pneumoperitoneum of radiological discovery in a patient of 16 years old boy, sickle-cell of type SS, during the exploration of an angiocholitis. It was medically treated successfully. No obvious etiology had been found. This particular situation is a dogma which runs up against the classic interventionist spirit; therefore each of pneumoperitoneum needs to be studied case by case. The presence of signs of peritoneal irritation allows surgical exploration. Otherwise, laparoscopy seems to be a minimally invasive surgical method and allows a visual diagnosis by eliminating a hollow organ perforation.
\end{abstract}

\section{Keywords}

Pneumoperitoneum, Spontaneous, Idiopathic, Laparoscopy

\section{Introduction}

Pneumoperitoneum is the abnormal presence of free gas in the peritoneal cavity, but outside the hollow viscera. In most cases, it is associated with hollow organs perforation and requires emergency surgery [1]. Nevertheless, cases of spontaneous pneumoperitoneum, without perforation of the gastrointestinal tract have been reported [2]. It constitutes an exceptional situation in paediatric population. The spontaneous or non-surgical pneumoperitoneum has several aetiolo- 
gies but can also be idiopathic. So, it is important to recognize and treat it appropriately because laparotomy and general anaesthesia are associated with significant morbidity. It has a benign course and can be treated medically [3]. We report a case of idiopathic pneumoperitoneum in a sickle cell of type SS, who successfully received medical treatment.

\section{Case Description}

It was a 16-year-old boy, sickle-cell of type SS, who consulted on February 2017, for fever and abdominal pain progressing since 72 hours before admission. The unquantified fever (initial symptom) was accompanied by chills and food vomiting, as well as epigastric and right hypochondrium pain. The transit was retained. He had benefited in town of multiple treatments made of quinine, ampicillin, and phloroglucinol. The initial examination had noted: alteration of general condition, systemic inflammatory response syndrome, respiratory distress syndrome, bilateral pulmonary condensation syndrome, the volume of the abdomen is normal and depressible as a whole, but sensitive in the right hypochondrium and the epigastrium, presence of a slight hepatomegaly and a negative Murphy sign. He had a hypochromic microcytic anemia at $3.2 \mathrm{~g} / \mathrm{dL}$ and hyperleucocytosis at $28.2 \mathrm{G} / 1$ predominantly neutrophilic at $22.8 \mathrm{G} / \mathrm{l}$. Pulmonary $\mathrm{X}$-ray showed diffuse flocculent opacities of the two pulmonary fields and pneumoperitoneum under the right hemidiaphragm (Figure 1). Plain abdominal radiography had objectified a clarity projected on the right hypochondrium with some hydro-aeric images, multiple calcic opacities projected on the vesicular area (Figure 2(a)). In the course of exploring the pneumoperitoneum, an oesogastroduodenal fibroscopy performed showed a congestive and erosive bulbitis without perforation of the upper digestive tract (Figure 3). The CT scan of the abdomen showed a giant pneumoperitoneum without fluid effusion, calcifications in the gallbladder without thickening of the wall, and homogeneous hepatomegaly (Figure 4 and Figure 5). The diagnosis of pulmonary (broncho-pneumonia) and digestive (angiocholitis) sepsis was discussed. Under tri-antibiotic IV therapy (thiamphenicol, amoxicillin and azithromycin), recovery was progressively favourable. The fever and abdominal pain regressed with leucocytosis passing from $28.2 \mathrm{G} / \mathrm{l}$ to $10.7 \mathrm{G} / \mathrm{l}$. The patient left the hospital 15 days

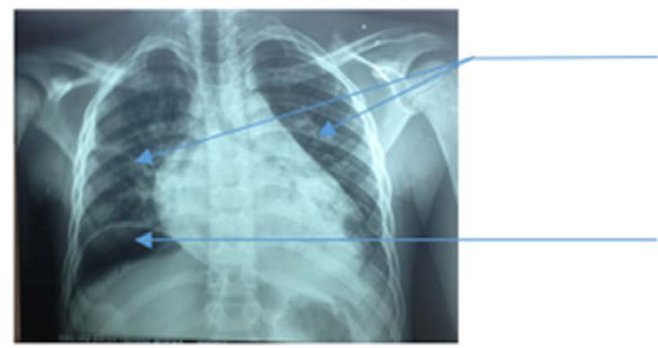

\section{Flaky opacities of the two pulmonary parenchyma}

Clarity under right
diaphragm
(Pneumoperitoneum)

Figure 1. AP Pulmonary x-ray showing flaky opacities of the two pulmonary parenchyma and clarity under right diaphragm. 


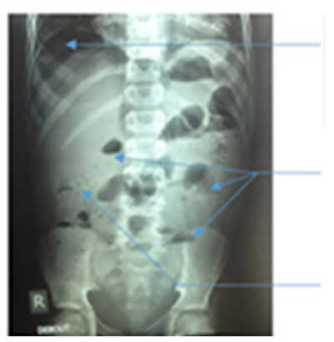

(a)

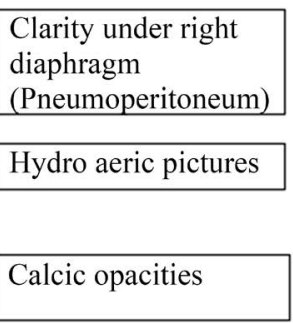

Calcic opacities

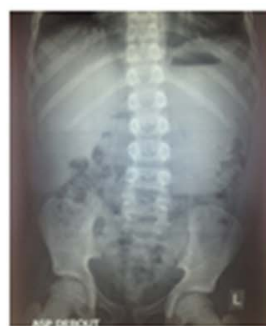

(b)

Figure 2. Upright AP abdominal X-ray. (a) First upright AP abdominal X-ray at the admission showing clarity under right diaphragmatic, hydroaeric pictures and calcic opacities projected on the vesicular area. (b) Second upright AP abdominal X-ray performed after two months was normal.

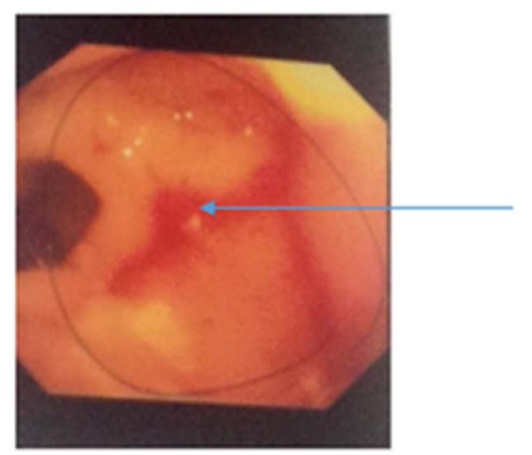

\begin{tabular}{l|} 
Mucosa of bulb \\
congestion and erosion
\end{tabular}

Figure 3. Oeso-gastro duodenal fibroscopy showing a mucosa of bulb congestion and erosion.

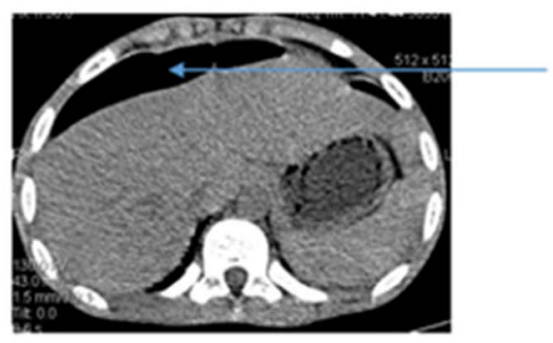

\author{
Pre-hepatic \\ hypodensity \\ (Pneumoperitoneum)
}

Figure 4. abdominal computed tomography (cross section) showing pre-hepatic hypodensity.

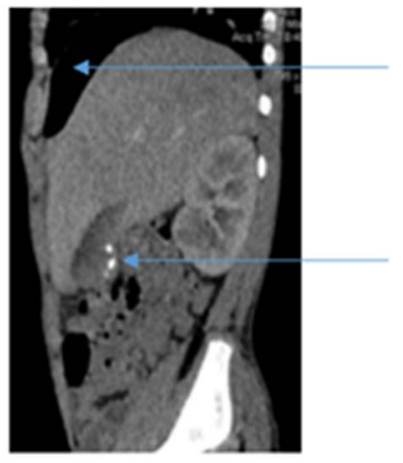

Pre-hepatic

hypodensity

(Pneumoperitoneum)

Intra vesicular hyper

density (Vesicular

calcifications)

Figure 5. abdominal computed tomography (para right sagittal) showing pre-hepatic hypodensity and intra vesicular hyperdensity. 
later after medical treatment without any clinical symptoms. The aetiology of the pneumoperitoneum was not found. The control of the plain abdominal radiograph done two months after the symptomatology was normal (Figure 2(b)).

Table 1 shows the summary of the clinical case.

\section{Discussion}

Pneumoperitoneum is a most common radiological sign of perforation of the gastrointestinal tract. The most often encountered aetiologies are dominated by appendix perforations, diverticulum, peptic ulcer, intestinal ischemia and post-traumatic [4]. They urgently require surgical exploration if there are signs of peritoneal irritation.

However, in $5 \%$ to $14 \%$ of pneumoperitoneum cases, no perforation is found [5]: it is spontaneous or non-surgical pneumoperitoneum. In adults, several of these cases have been reported in the literature [6] [7]. In children, it is a very rare situation. It was the case of a 7-month-old girl with medical history of partial agenesis of the corpus callosum and a psychomotor retardation who presented a 3 days history of fever, partial rejection of ingestion and irritability. The clinical and paraclinical explorations concluded to a perforation and she benefited from a laparotomy which found no cause of pneumoperitoneum. She also benefited from a prophylactic appendicectomy [2].

The aetiologies of spontaneous pneumoperitoneum are numerous.

Table 1. Sociodemographic characteristics and signs.

\begin{tabular}{|c|c|}
\hline & Case description \\
\hline Age & 16 years \\
\hline Sex & Male \\
\hline $\begin{array}{l}\text { Circumstances } \\
\text { of occurred }\end{array}$ & Fever and abdominal pains \\
\hline Current disease & Sickle-cell type SS \\
\hline \multirow{4}{*}{ Signs } & $\begin{array}{l}\text { Clinical signs: food vomiting, general state alteration syndrome, systemic } \\
\text { inflammatory response syndrome, respiratory distress syndrome, bilateral } \\
\text { pulmonary condensation syndrome, sensitive in the right hypochondrium } \\
\text { and the epigastrium } \\
\text { Blood test results: anemia and hyperleucocytosis } \\
\text { Pulmonary X-ray: diffuse flocculent opacities of the two pulmonary fields } \\
\text { and pneumoperitoneum under the right hemidiaphragm }\end{array}$ \\
\hline & $\begin{array}{l}\text { Plain abdominal radiograph: clarity projected on the right } \\
\text { hypochondrium with some hydro-aeric images, multiple calcic opacities } \\
\text { projected on the vesicular area }\end{array}$ \\
\hline & $\begin{array}{l}\text { Oesogastroduodenal fibroscopy: congestive and erosive bulbitis without } \\
\text { perforation of the upper digestive tract. }\end{array}$ \\
\hline & $\begin{array}{l}\text { Abdominal computed tomography: giant pneumoperitoneum without } \\
\text { fluid effusion, calcifications in the gallbladder without thickening of the } \\
\text { wall, and homogeneous hepatomegaly }\end{array}$ \\
\hline Treatment & tri-antibiotic IV therapy \\
\hline Evolution & favorable \\
\hline
\end{tabular}


At the abdominal level, open abdominal surgery and laparoscopy were found in $60 \%$ and $25 \%$ of cases [8]. Pneumocholecystitis [9], aerophagia and endoscopic explorations are also cited. In children, cystic intestinal pneumatosis is found, which may be primary or revealing of certain pathologies such as necrotizing enterocolitis, peptic ulcers, pyloric obstructions, intestinal occlusions, inflammatory intestinal diseases [10]. It is characterized by the presence of cyst filled with air in the intestinal wall [11]. From the aetiopathogenic point of view, it has been described in the literature a mechanical theory in which the air comes from the thorax by perivascular pathways and a bacterial theory according to which the gas is produced by bacteria in the intestinal mucosa [11]. These gas cysts can then break into the peritoneal cavity and cause acute abdominal pain that can simulate an acute abdomen.

At the thoracic level, we find barotrauma, pneumothorax, chronic obstructive pulmonary disease and cardiopulmonary resuscitation. In children, pneumoperitoneum occurs in $1 \%$ - $3 \%$ of cases of mechanical ventilation in premature infants [12].

At the gynaecological level, there are inflammatory gynaecological diseases and sexual abuse [12].

Apart from these cases of spontaneous pneumoperitoneum linked to an aetiology, there are patients in whom no aetiology is found.

These are idiopathic pneumoperitoneum. In our patient, no aetiology of the pneumoperitoneum is found.

From the therapeutic point of view, the presence of signs of peritoneal irritation imposes a surgical indication. Otherwise, non-surgical treatment is indicated [3]. Of 196 cases of spontaneous pneumoperitoneum reported by Mularski, 45 underwent surgical exploration; and all were uneventful [12]. This situation confirms the case presented by Fortes et al. [2]. Today, laparoscopy is the golden standard in the exploration of spontaneous pneumoperitoneum. It makes it possible to find and treat aetiologies; but also has the advantage of being less invasive than conventional laparotomy [13].

In our patient's case, a past history of sickle-cell type SS and angiocholitis has not been found in the literature as an aetiology of pneumoperitoneum. Despite the existence of a massive pneumoperitoneum, medical treatment has allowed a complete amendment of the clinical, biological and radiological signs confirming the data of the literature.

\section{Conclusion}

Pneumoperitoneum is a sign most often associated with perforation of the gastrointestinal tract. There are cases of pneumoperitoneum without intestinal perforation called "spontaneous" or "non-surgical". This particular situation constitutes a dogma which runs up against the interventionist spirit and will have to be studied case-by-case. The presence of signs of peritoneal irritation allows surgical exploration. Otherwise, laparoscopy and medical treatment are required. 
The case of our patient illustrates the existence of idiopathic pneumoperitoneum, but must be a diagnosis of exclusion.

\section{Disclosure}

The authors declare no conflicts of interest.

\section{References}

[1] Pitiakoudis, M., Zezos, P., Oikonomou, A., Kirmanidis, M., Kouklakis, G. and Simopoulos, C. (2011) Spontaneous Idiopathic Pneumoperitoneum Presenting as an Acute Abdomen: A Case Report. Journal of Medical Case Reports, 5, 86. https://doi.org/10.1186/1752-1947-5-86

[2] Fortes, L.M., González, M.G., Mata, N.C., Beloy, I.C., Dono, I.S. and Argibay, I.S. (2017) Idiopathic Pneumoperitoneum in a Pediatric Patient: A Case Report. ARC Journal of Clinical Case Reports, 3, 9-12.

[3] Karaman, A., Demirbilek, S., Akin, M., Gürünlüoglu, K. and Irsi, C. (2005) Does Pneumoperitoneum Always Requiste Laparotomy? Report of Six Cases and Review of Literature. Pediatric Surgery International, 21, 819-824. https://doi.org/10.1007/s00383-005-1489-3

[4] Kumar, A., Muir, M.T., Cohn, S.M., Salhanick, M.A., Lankford, D.B. and Katabathina, V.S. (2012) The Etiology of Pneumoperitoneum in the 21st Century. Journal of Trauma and Acute Care Surgery, 73, 542-48. https://doi.org/10.1097/TA.0b013e31825c157f

[5] Winek, T.G., Mosely, H.S., Grout, G. and Luallin, D. (1988) Pneumoperitoneum and Its Association with Ruptured Abdominal Viscus. The Archives of Surgery, 123, 709-712. https://doi.org/10.1001/archsurg.1988.01400300051008

[6] Kadkhodaie, H.R. and Vaziri, M. (2008) Asymptomatic Spontaneous Pneumoperitoneum. Shiraz E-Medical Journal, 9, 198-200.

[7] Ponomarenko, O., Sibirsky, O. and Susmallian, S. (2012) Pneumoperitoneum Is Not Always an Indication for Laparotomy: A Case Report. IJCRI, 3, 39-42.

[8] Stapakis, J.C. and Thickman, D. (1992) Diagnosis of Pneumoperitoneum: Abdominal TC vs Upright Chest Film. Journal of Computer Assisted Tomography, 16, 713-716. https://doi.org/10.1097/00004728-199209000-00008

[9] Watson, D.I., Isaacs, J. and William, R.S. (1994) Emphymatous Cholecystitis Can Cause Pneumoperitoneum. ANZ Journal of Surgery, 64, 130-131. https://doi.org/10.1111/j.1445-2197.1994.tb02161.x

[10] Alassaf, M. (2014) Recurring Spontaneous Aseptic Pneumoperitoneum Presenting Secondary to an Unrelated Chief Compliant: A Case Report. International Journal of Surgery Case Reports, 7, 96-98. https://doi.org/10.1016/j.ijscr.2014.10.038

[11] Longo, W.E., Ballantyne, G.H. and Graham, A.J. (1987) Pneumatosis Cystoides Intestinalis: Presentation as an Acute Abdomen. Journal of Clinical Gastroenterology, 9, 487-489. https://doi.org/10.1097/00004836-198710000-00019

[12] Mularski, R.A., Sippel, J.M. and Osborne, M.L. (2000) Pneumoperitoneum: A Review of Nonsurgical Causes. Critical Care Medicine, 28, 2638-2644. https://doi.org/10.1097/00003246-200007000-00078

[13] Sebastian-Valverde, E., Membrilla-Fernández, E., Argudo-Aguirre, N., Pons-Fragero, M.-J. and Sancho-Insenser, J.J. (2015) Is the Conservative Treatment the Choice for the Spontaneous Pneumoperitoneum? Journal of Case Reports and Images in Surgery, 1, 5-8. 